\title{
Investigation of Ruminant Xenobiotic Metabolism in a Modified Rumen Simulation System (RUSITEC)
}

\author{
Barbara Birk 1,2, Alexander Stähle 1, Mathias Meier 1, Markus Palm 1, Dorothee Funk-Weyer 1, Gerhard Breves ${ }^{3}$ \\ and Harald Seulberger 1 \\ ${ }^{1}$ BASF SE Global Environmental \& Consumer Safety, Crop Protection, Limburgerhof, Germany; ${ }^{2}$ BASF SE Experimental Toxicology and Ecology, \\ Ludwigshafen am Rhein, Germany; ${ }^{3}$ University of Veterinary Medicine Hannover, Foundation, Institute of Physiology, Hannover, Germany
}

\begin{abstract}
The approval of plant protection agents requires xenobiotic metabolism and residue studies in rats, farm animals and plants (e.g., EU regulation 1107/2009) performed according to OECD guidelines. The intestinal metabolism of ruminants can produce specific residues, which must be investigated in detail. This is usually done by performing additional in vivo studies. The aim of the present work is to assess whether a modified in vitro rumen simulation system (RUSITEC) can generate this information. Rumen constituents from sheep were incubated over 8 days. The pH $(6.70 \pm 0.07)$, the redox potential $(301 \mathrm{mV} \pm 30 \mathrm{mV})$, the microbial composition, and $\beta$-glucosidase activity were monitored. After an equilibration period of four or five days the fermenters were probed with ${ }^{14} \mathrm{C}$-labelled triazole derivatives, i.e., common metabolites of azole fungicides. Only triazole-alanine was cleaved to 1,2,4-triazole, while triazole-acetic acid and triazole-lactic acid remained stable for up to 96 hours. The two glucosides octyl- $\beta$-D-glucopyranoside and polydatin, which are common residues found in plants, were both rapidly cleaved in the in vitro rumen system. The data shows that the modified RUSITEC system is stable, viable and maintains metabolic capacity over a longer period of time (at least 8 days). This makes many animal experiments obsolete and represents a significant contribution to the 3 Rs (refine, reduce, replace). The modification of the RUSITEC system enables safe use of unlabeled but also of radiolabeled test compounds.
\end{abstract}

\section{Introduction}

In the development of plant protection products extensive tests are required by the approving agencies such as, e.g., the European Food and Safety Agency (EFSA) in Europe and the United States Environmental Protection Agency (US-EPA) in the US, to prove the safety of the product to the environment, animals and humans. Xenobiotic metabolism studies in rats, farm animals and plants identify and quantify the active ingredient and its related degradation products, i.e. metabolites.

The active ingredient or metabolites of the product may enter the food chain; therefore, a detailed assessment of the quality and quantity of the residues is required. The results are compared with the results of rat metabolism studies to determine the appropriate coverage of the relevant metabolites by toxicological studies in rats (EFSA, 2016). If they are not covered, additional toxicological studies are required. All xenobiotic metabolism studies are performed according to OECD TG 417 (rat; OECD, 2010), 503 and 505 (farm animals; OECD, 2007a,b), 501 and 502 (plants; OECD, 2007c,d).
Based on the outcome of these studies, specific aspects of xenobiotic metabolism in ruminants may arise: 1) Are the observed metabolites ruminant-specific and formed directly in the rumen? 2) Are ruminants able to cleave plant specific metabolites like glycosides to the respective aglycon? These questions are commonly investigated by performing additional in vivo studies in ruminants according to OECD 503 (OECD, 2007a), which are treated with radiolabeled test item, housed in metabolic cages for at least 5 days, and sacrificed at the end of the study.

To avoid these animal experiments in the future and contribute significantly to the $3 \mathrm{R}$ principle, a method to replace this type of study was developed by adapting and improving an existing method called the rumen simulation technique RUSITEC. Ruminant metabolism differs from that of other animals and man with regard to the forestomach system (anaerobic conditions) and specific contribution of microorganisms, e.g., to cellulose degradation as reported by Czerkawski and Breckenridge (1977).

A rumen simulation system (RUSITEC) is an in vitro system containing rumen, solid feed and buffer incubated under anaer-
Received December 22, 2017; Accepted February 26, 2018; Epub March 12, 2018; @ The Authors, 2018.

ALTEX 35(3), 379-389. doi:10.14573/altex.1712221

Correspondence: Barbara Birk, PhD, BASF SE Experimental Toxicology and Ecology, Z570, Room 207, Carl-Bosch Str. 38, 67056 Ludwigshafen am Rhein, Germany

(barbara.birk@basf.com)
This is an Open Access article distributed under the terms of the Creative Commons Attribution 4.0 International license (http://creativecommons.org/licenses/by/4.0/) which permits unrestricted use, distribution and reproduction in any medium, provided the original work is appropriately cited. 
obic conditions at $39^{\circ} \mathrm{C}$. In the past, this method was mainly used to measure methane production (Becker, 2012) or the contribution of microbes to metabolism (Oeztuerk et al., 2005). In the present study, the original RUSITEC was further refined to make it safer and easier to use for routine analysis of xenobiotic metabolism, including handling of radiolabeled compounds. The modifications were performed with the aim to establish an in vitro test system to avoid extensive animal experiments to test plant protection agents (Clippinger et al., 2016).

To answer whether the observed metabolites are ruminant-specific and are formed directly in the rumen, the metabolism of triazole derivative metabolites (TDM) was investigated. Azoles are developed and produced by different companies and represent a widely used group of fungicides in agriculture. The azoles form common metabolites, i.e., triazole derivative metabolites (TDM) (Stroeher-Kolberg et al., 2014; FAO, 2007; TDMDG, 2016). The toxicological properties of TDMs and their xenobiotic metabolites are of concern to the agencies and therefore additional safety studies are required (EFSA, 2015; TDMDG, 2016).

To answer whether ruminants can cleave plant specific metabolites like glycosides to the respective aglycon, the metabolism of glucoside conjugates was investigated. Glycosides are important plant constituents (Jenner et al., 2005; Bennett and Wallsgrove, 1994) and rumen contains microorganisms with $\beta$-glucosidase activity that can potentially cleave the glycosides to the respective aglycon. Radioactively labelled octyl- $\beta$-D-glucopyranoside was used as a model compound to analyze the stability and enzymatic activity of the in vitro system. Polydatin, the glucoside-derivative of resveratrol, was used to study the metabolism of a non-labeled compound.

\section{Animals, materials and methods}

\subsection{Animals}

The three sheep used in this study were housed on a farm of the "Landwirtschaftliche Untersuchungs- und Forschungsanstalt (LUFA)" in Speyer, Germany. The animals were fed hay and concentrate, housed individually with contact to each other and bedded on straw. Animals were checked on a daily basis for any signs of discomfort by the trained staff ( $>30$ years experience) and inspected regularly by a veterinarian. The sheep were fitted with permanent rumen cannulas (approved by the ethics committee at Niedersächsisches Landesamt für Verbraucherschutz und Lebensmittelsicherheit (LAVES) Reference Number. 33.442502-04-13A373). The animals are used to the procedure due to regular sampling for tests on animal feed, so the sampling (performed within $5 \mathrm{~min}$ ) of the rumen fluid did not appear to stress the animals. Beside the liquid rumen, solid rumen constituents, which accumulate in the cannulas, were collected into pre-warmed isolated flasks (neoLab-Weithals-Isoliergefäß; neoLab Migge Laborbedarf-Vertriebs GmbH, Heidelberg, Germany). The liquid rumen was withdrawn by aspiration and approx. $400 \mathrm{ml}$ from each sheep combined into another isolated flask (neoLab-Edelstahl-Isolierflasche 1,0 1; neoLab Migge
A

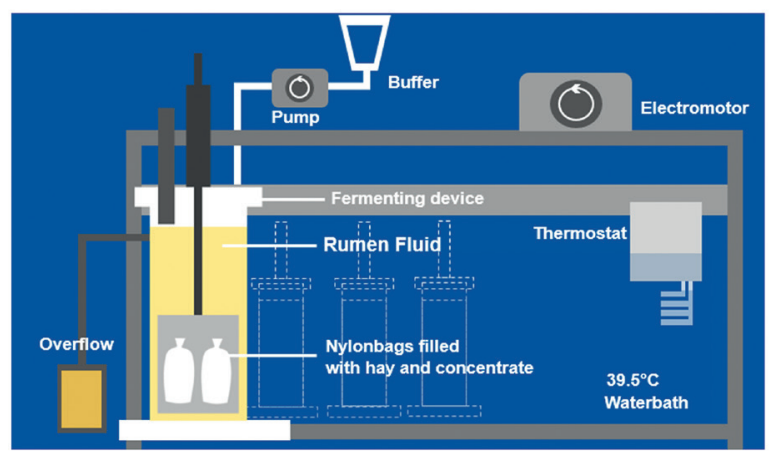

B

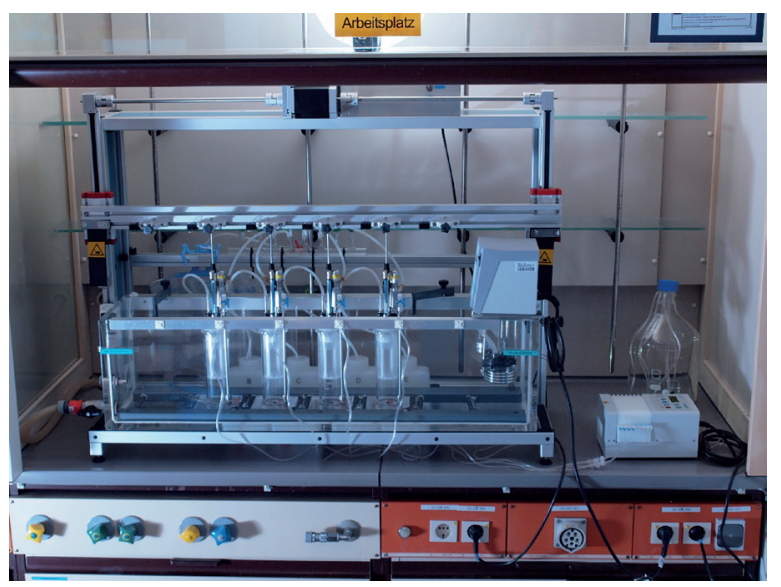

C

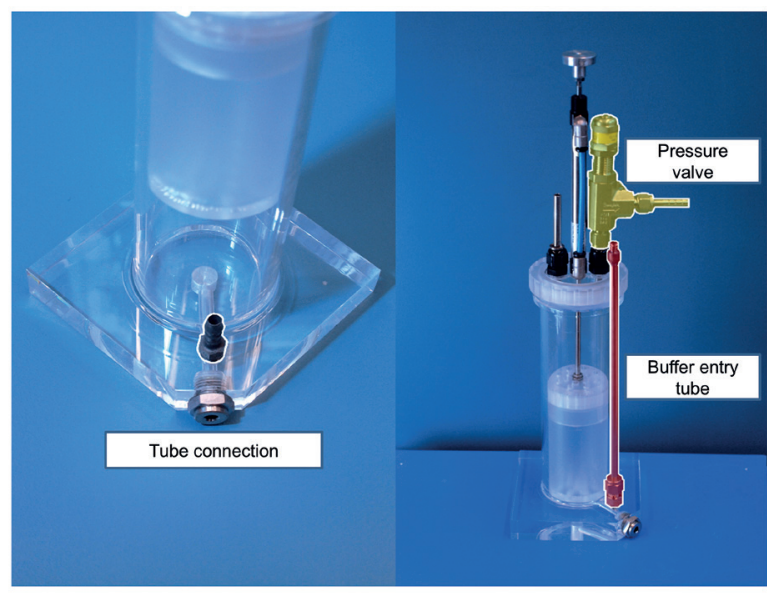

Fig. 1: The RUSITEC system

A, Schematic of the RUSITEC system; B, Photograph of the RUSITEC system; C, RUSITEC system modified by BASF. 
Laborbedarf-Vertriebs GmbH, Heidelberg, Germany). Prior to being filled, all flasks were rinsed with nitrogen to enable anaerobic conditions. The transport to the laboratory generally took no more than $30 \mathrm{~min}$. However, it has been observed in internal studies (data not shown) that the rumen fluid is stable also over a longer period $(\sim 3 \mathrm{~h})$.

\subsection{Modified RUSITEC system}

The classical RUSITEC system uses volumes between 500 and $1000 \mathrm{ml}$ (Lengowski et al., 2016; Becker, 2012; Oetztuerk et al., 2005; Czerkawski and Breckenridge, 1977). For the purpose described herein, where the metabolism of radioactively labelled compounds was to be analyzed, the system was reduced to a smaller volume of $250 \mathrm{ml}$. Further, the connections within the system were made safer to correspond to radiosafety requirements (Fig. 1A,B). The tubing connecting the buffer reservoir with the fermenter was changed to medical supplies and luer-lock connections (ZVD-Messsystem; Sarstedt AG \& Co. $\mathrm{KG}$, Nümbrecht, Germany). This enabled affordable sterile and single use tubing. The original plastic tube for the buffer was replaced by a $25 \mathrm{~cm}$ long steel tube soldered to a luer-lock connection. This enabled an easy and safe daily change of the nylon feed bags without the risk of radioactive spillage (Fig. 1C). Six fermenters were placed in a water bath kept at $39.5^{\circ} \mathrm{C}$ by means of a thermostat (ED; JULABO GmbH, Seelbach, Germany) and monitored and documented with a temperature data logger (EBI 300; ebro Electronic GmbH, Ingolstadt, Germany) and an external sensor (TPC 300; ebro Electronic GmbH) (Fig. 1A). The simulation of stomach movement was achieved with a motor so that the buffer was pumped into the fermenter at a speed of $0.174 \mathrm{ml} / \mathrm{min}$, leading to a total exchange of liquid phase in $24 \mathrm{~h}$ (ISM 931; ISMATEC Laboratoriumstechnik GmbH, Wertheim-Mondfeld, Germany). The overflow from each fermenter was collected into Nalgene bottles (Nalgene-HDPEflask square 1 1; Thermo Fisher Scientific Inc., Waltham, MA, USA). Gas arising in the fermentation was not collected for this study but could escape through two $1 \mathrm{~mm}$ holes in the lids. A third hole was fitted with a pressure valve (Proportional Relief Valve SS-RL3S6MM; Swagelok Company, Solon, OH, USA) to avoid any leakage due to blockage of the tubing. The valve would open at pressures above 1 bar to release liquids and gas into a receptacle (UD 3 TUR-BAG 4 1; Sarstedt AG \& Co. KG, Nümbrecht, Germany). Before the start of the experiments the fermenters were dismantled and cleaned by ultrasonication for $10 \mathrm{~min}$ (Elmasonic S30H; Elma Schmidbauer GmbH, Singen, Germany) in 5\% deconex 20 NS-x (Borer Chemie AG, Zuchwil, Switzerland), washed in deionized water, air dried and fitted together.

\subsection{Experimental design}

\section{RUSITEC buffer}

$\mathrm{NaCl} 28 \mathrm{mM}, \mathrm{KCl} 7.69 \mathrm{mM}, \mathrm{CaCl}_{2} 0.22 \mathrm{mM}, \mathrm{MgCl}_{2} 0.63 \mathrm{mM}$, $\mathrm{HCl} 0.5 \mathrm{mM}, \mathrm{NaH}_{2} \mathrm{PO}_{4} 10 \mathrm{mM}, \mathrm{Na}_{2} \mathrm{HPO}_{4} 10 \mathrm{mM}, \mathrm{NH}_{4} \mathrm{Cl}$ 5 mM, $\mathrm{NaHCO}_{3} 97.9$ mM, pH 7.35 (Becker, 2012; Oetztuerk et al., 2005).
Feed

To mimic regular feed intake, $2.5 \mathrm{~g}$ hay (Dein Bestes - AlpenWiesenheu; dm-drogerie markt $\mathrm{GmbH} \& \mathrm{Co}$. KG, Karlsruhe, Germany) and $1 \mathrm{~g}$ pellets (sheep fodder S2; Raiffeisen-Kraftfutterwerk Mittelweser Heide GmbH, Hoya, Germany) were filled into nylon bags with $50 \mu \mathrm{m}$ mesh (In-Situ-Bags $5 \times 10 \mathrm{~cm}$ R510; ANKOM Technology, Macedon, NY, USA), closed and stored in Nalgene bottles at room temperate until use. Prior to filling, hay was ground for $7 \mathrm{~s}$ at $7000 \mathrm{U} / \mathrm{min}$ (Grindomix GM 200; RETSCH GmbH, Haan, Germany) into particles of different sizes. The pellets were ground in a mortar. This particle distribution was intended to mimic rumination and thus the content of the rumen in an intact animal.

\section{Liquid and solid rumen content}

The liquid rumen was filtered through a viscose cloth (Tork Long-Lasting Cleaning Cloth 90477; SCA GmbH, Ismaning, Germany). Then the $\mathrm{pH}$ and the redox potential of the filtrate was determined (see below) and $250 \mathrm{ml}$ filled into each of four fermenters. The contents of two nylon bags with feed were filled into the fermenters. To one of these $7 \mathrm{~g}$ of solid rumen contents were added to inoculate with bacteria associated with solids. The fermenters were placed into the water bath and connected to the pump and buffer reservoir and the motor was set at three strokes/ min to imitate peristaltic movement. The bag containing the solid rumen constituents was changed to a fresh feeder bag after $24 \mathrm{~h}$, the second one after $48 \mathrm{~h}$, such that each feeder bag was in the fermenter for $48 \mathrm{~h}$ and one was changed each day. Over the entire experimental period, $\mathrm{pH}$ and redox potential were determined in samples collected at the same time and stored at $-20^{\circ} \mathrm{C}$.

\section{Incubations}

To equilibrate the system, a pre-incubation for four or five days was performed during which $\mathrm{pH}$, redox potential, particles and colony formation, protozoa and glucosidase activity were monitored (details see below). During this phase a stable population of microorganisms adapted to the in vitro conditions is achieved (Lengowski et al., 2016; Becker, 2012; Martínez et al., 2011). The amount of compound to be added was calculated under consideration of the efflux according to the following formula:

$$
\begin{aligned}
& \frac{\mathrm{dS}}{\mathrm{dt}}=-\left(\frac{0.174}{250}\right) \mathrm{S} \\
& \mathrm{S}(\mathrm{t})=\mathrm{S}(0) * \mathrm{e}^{-\left(\frac{0.174}{250}\right) \mathrm{t}}
\end{aligned}
$$

$\mathrm{S}$ : Amount of substrate in fermenter; $\mathrm{t}$ : time after addition; 0.174 : efflux rate in $\mathrm{ml}$; 250: volume of one fermenter in $\mathrm{ml}$

The compounds used to examine the metabolism of the plant metabolites of azole-fungicides (Stroeher-Kolberg et al., 2014; FAO, 2007) were ${ }^{14} \mathrm{C}$-labelled triazole-alanine (TA), triazole-acetic acid (TAA) and triazole-lactic acid (TLA) (Tab. 1). The test compounds were synthesized in the BASF SE isotope 
Tab. 1: Reference compounds (TDM)

\begin{tabular}{|l|l|l|}
\hline & Name & triazole-alanin (TA) \\
\cline { 2 - 3 } & Formula & $\mathrm{C}_{5} \mathrm{H}_{8} \mathrm{~N}_{4} \mathrm{O}_{2}$ \\
\hline & Specific activity & $0.02 \mathrm{MBq} / \mathrm{mg}$ \\
\hline & Amount added & $78.4 \mathrm{mg}$ \\
\cline { 2 - 3 } & Dissolved in & $2.5 \mathrm{ml} \mathrm{VE}-\mathrm{H}_{2} \mathrm{O}$ \\
\hline
\end{tabular}

\begin{tabular}{|l|l|l|}
\hline & Name & triazole-acetic acid (TAA) \\
\cline { 2 - 3 } & Formula & $\mathrm{C}_{4} \mathrm{H}_{5} \mathrm{~N}_{3} \mathrm{O}_{2}$ \\
\cline { 2 - 3 } & Specific activity & $0.02 \mathrm{MBq} / \mathrm{mg}$ \\
\cline { 2 - 3 } & Amount added & $72.0 \mathrm{mg}$ \\
\cline { 2 - 3 } & Dissolved in & $2.5 \mathrm{ml} \mathrm{VE}-\mathrm{H}_{2} \mathrm{O}$ \\
\hline
\end{tabular}

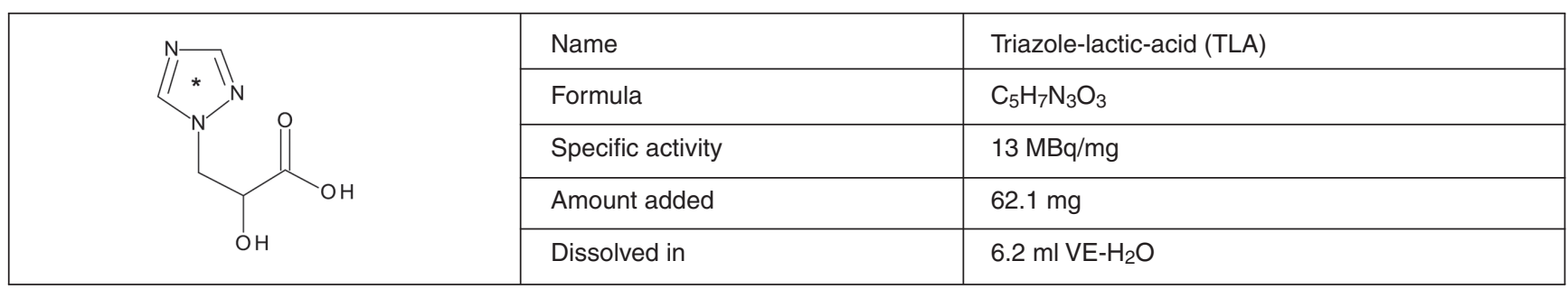

$\left.{ }^{*}\right)$ marks labelling with ${ }^{14} \mathrm{C}$

laboratory and were labelled in the ring carbons of the triazole (formula specific activities and dosing see Tab. 1). The compounds were added each to one fermenter after the equilibration phase of $96 \mathrm{~h}$. Samples of $2 \mathrm{ml}$ were withdrawn after $4 \mathrm{~h}, 8 \mathrm{~h}$, $24 \mathrm{~h}, 48 \mathrm{~h}, 72 \mathrm{~h}$ and $96 \mathrm{~h}$, aliquoted into 2 Eppendorf tubes with $250 \mu 1$ acetonitrile, vortexed (Reax 2000; Heidolph Instruments GmbH \& Co.KG, Schwabach, Germany), and centrifuged for 5 min (Mikro 200; Andreas Hettich GmbH \& Co.KG, Tuttlingen, Germany). The supernatant was transferred to fresh Eppendorf tubes and stored at $-20^{\circ} \mathrm{C}$ until analysis.

As model compounds for plant glycosides the ${ }^{14} \mathrm{C}$-labelled octyl- $\beta$-D-glucopyranoside (American Radiolabeled Chemicals Inc., St. Louis, MO, USA) (unlabeled octyl- $\beta$-D-glucopyranoside was from Sigma-Aldrich Chemie GmbH, Steinheim, Germany) and the unlabeled glycoside of resveratrol, polydatin (Sigma-Aldrich Chemie $\mathrm{GmbH}$ ) were incubated in the modified RUSITEC system (Tab. 2). The compounds were added after $120 \mathrm{~h}$ equilibration. Rapid cleavage of octyl-glucoside by glycosidase was observed, therefore samples were taken at shorter intervals after $5 \mathrm{~min}, 10 \mathrm{~min}, 15 \mathrm{~min}, 30 \mathrm{~min}, 1 \mathrm{~h}, 2 \mathrm{~h}, 4 \mathrm{~h}, 6 \mathrm{~h}$, $24 \mathrm{~h}, 48 \mathrm{~h}$ and $72 \mathrm{~h}$.

\subsection{Analytical methods}

Determination of $\mathrm{pH}$ and redox potential

These were determined daily directly in the cultivated rumen fluid when the fermenter was opened to change feed bags. The
$\mathrm{pH}$ was determined using a portable $\mathrm{pH}$-meter (SG2 SevenGo; Mettler Toledo, Schwerzenbach, Switzerland) and a pH-electrode (InLab Expert Pro ISM; Mettler Toledo), the redox potential with a redox-electrode (LE 510; Mettler Toledo) after equilibration for $1 \mathrm{~min}$.

\section{Viability tests}

Samples of $1 \mathrm{ml}$ were taken at the start of the fermentation, after equilibration $(96 \mathrm{~h})$ and at the end of the experiment after 168 h. Rumen was diluted 1:100, 1:1000, 1:10,000 and applied to agar plates (CASO-AbklatschA +LTH - RT+; heipha Dr. Müller $\mathrm{GmbH}$, Eppelheim, Germany) and incubated for $24 \mathrm{~h}$ at $39^{\circ} \mathrm{C}$ (ED 23; BINDER GmbH, Tuttlingen, Germany) under anaerobic conditions (AnaeroGen W-Zip COMPACT; Oxoid Ltd, Basingstoke, UK). Colonies were counted after incubation (Modell 950 c; Fa. Schuett, Göttingen, Germany).

\section{Determination of particles}

Samples were analyzed every $24 \mathrm{~h}$ with an automatic Coulter counter (Moxi Z; ORFLO Technologies, Ketchum, ID, USA) in thin layer cassettes type S (MXC002; ORFLO Technologies) in the small particle mode. This setting measures particles of 2-10 $\mu \mathrm{m}$ diameter. Rumen contains particles between 0.4 and $10 \mu \mathrm{m}$ diameter and some protozoa and flagellates have a diameter between 4 and $14 \mu \mathrm{m}$ (Breves and Leonhard-Marek, 2010; Hungate, 1966). This method should therefore register any changes in the microbial composition of the rumen, taking into account 
Tab. 2: Reference compounds (glycosides)

\begin{tabular}{|l|l|}
\hline Name & Octyl $\beta$ D glucopyranoside \\
\hline Formula & $\mathrm{C}_{14} \mathrm{H}_{28} \mathrm{O}_{6}$ \\
\hline Specific activity & $0.07 \mathrm{MBq} / \mathrm{mg}$ \\
\hline Amount added & $108 \mathrm{mg}$ \\
\hline Dissolved in & $2.5 \mathrm{ml} \mathrm{RUSITEC}$-buffer \\
\hline
\end{tabular}

\begin{tabular}{|c|c|}
\hline Name & Polydatin \\
\hline Formula & $\mathrm{C}_{20} \mathrm{H}_{22} \mathrm{O}_{8}$ \\
\hline Amount added & $\begin{array}{l}142 \text { mg (Fermenter A) } \\
15 \text { mg (Fermenter B) }\end{array}$ \\
\hline Dissolved in & $\begin{array}{l}0.5 \mathrm{ml} \text { ethanol }+2 \mathrm{ml} \text { RUSITEC-buffer } \\
\text { (Fermenter } \mathrm{A} \text { ) } \\
100 \mu \mathrm{l} \text { ethanol }+2.4 \mathrm{ml} \text { RUSITEC-buffer } \\
\text { (Fermenter B) } \\
\text { after sonication }\end{array}$ \\
\hline
\end{tabular}

that no distinction is possible between live cells and other particles. Protozoa were counted every $24 \mathrm{~h}$ in a Neubauer chamber directly in $10 \mu 1$ rumen, recorded digitally (AxioCam MRc; Carl Zeiss Microscopy GmbH, Jena, Germany), and analyzed manually with the software AxiVision V. 4.9.1.0 (Carl Zeiss Microscopy $\mathrm{GmbH}$ ).

\section{Determination of $\beta$-glucosidase activity}

$\beta$-Glucosidase activity in the samples stored at $-20^{\circ} \mathrm{C}$ was determined by photometry at $405 \mathrm{~nm}$ (Synergy H1 Hybrid Reader; BioTek Instruments GmbH, Bad Friedrichshall, Germany) with 4-nitrophenol- $\beta$-D-glucopyranoside as substrate ( $\beta$-Glucosidase Activity Assay Kit MAK129; Sigma-Aldrich Chemie GmbH, Steinheim, Germany).

\section{Analysis of metabolites}

Metabolites of the triazoles and glycosides were separated by HPLC and quantified by flow through scintillation or UV detection as follows:
The HPLC system for analysis of TA, TAA and TLA was composed of a Dionex Ultimate 3000 pump, a Dionex UCI100 interface, a Dionex ASI-100 autosampler, and a Dionex STH 585 oven, steered by Gynkotek Chromeleon V6.80 SR5 software. For the ${ }^{14} \mathrm{C}$-labelled compounds a radio-detector (Berthold LB507A) and a pump (Berthold LB5036) were used. Column for the triazole derivatives: TCI Dual ODS-CX15, $250 \times 4.6 \mathrm{~mm}$. Solvent A: $\mathrm{H}_{2} \mathrm{O}: \mathrm{CF}_{3} \mathrm{COOH}(1000: 2.5)(\mathrm{v} / \mathrm{v})$, solvent $\mathrm{B}: \mathrm{H}_{2} \mathrm{O}: \mathrm{CH}_{3} \mathrm{CN}: \mathrm{CF}_{3} \mathrm{COOH}(5: 995: 2.5)(\mathrm{v} / \mathrm{v} / \mathrm{v})$, gradient: up to $15 \min 100 \% \mathrm{~A}, 15$ to $16 \min 100 \% \mathrm{~B}$, to $21 \mathrm{~min} 100 \% \mathrm{~B}$, $22 \mathrm{~min} 100 \%$ A, flow $1 \mathrm{ml} / \mathrm{min}$, oven temperature $24^{\circ} \mathrm{C}$. Injection volumes were increased from $75 \mu 1$ for samples withdrawn before $48 \mathrm{~h}$ to $100 \mu \mathrm{l}$ for TA and TAA analyses, TLA samples from $50 \mu \mathrm{l}$ at $4 \mathrm{~h}$ to $75 \mu \mathrm{l}$ thereafter. Octyl- $\beta$-D-glucopyranoside and its metabolites were analyzed on the following system: Dionex P680 pump, Dionex UCI-50 interface, Dionex UltiMate 3000 autosampler, Berthold LB509 radiodetector and Berthold LB5035 pump, oven and software as above. The column was a Nucleodur C18 ISIS, $250 \times 4.6 \mathrm{~mm}$, solvent A: $\mathrm{H}_{2} \mathrm{O}: \mathrm{CH}_{3} \mathrm{CN}$ : $\mathrm{HCOOH} \quad(950: 50: 1) \quad(\mathrm{v} / \mathrm{v} / \mathrm{v})$, solvent $\mathrm{B}: \mathrm{CH}_{3} \mathrm{CN}: \mathrm{HCOOH}$ $(1000: 1)(v / v)$, gradient: up to $5 \mathrm{~min} 100 \% \mathrm{~A}$, to $25 \mathrm{~min} 100 \% \mathrm{~B}$, $30 \mathrm{~min} 100 \% \mathrm{~B}, 30.1 \mathrm{~min} 100 \%$ A. Flow $1 \mathrm{ml} / \mathrm{min}$, temperature $25^{\circ} \mathrm{C}$, injection volume $40 \mu$. Polydatin and metabolites (e.g., resveratrol) were analyzed according to $\mathrm{Lv}$ et al. (2006), with the same HPLC system and detected on a Jasco UV-2075Plus detector at $306 \mathrm{~nm}$, the column was a Nucleodur C18 ISIS, $250 \times 4.6 \mathrm{~mm}$ and the solvent $\mathrm{CH}_{3} \mathrm{CN}: \mathrm{H}_{2} \mathrm{O}: \mathrm{HCOOH}(260: 740: 1)$ flow $1 \mathrm{ml} / \mathrm{min}$, temperature $25^{\circ} \mathrm{C}$, injection volume $20 \mu 1$ of $1: 2$ diluted samples..

\section{Statistics}

Means of the fermenters and SD were calculated with Excel 2013 (Version 15.0.4763.1003; Microsoft Corporation, Redmond, WA, USA). The numbers and the sizes of particles were determined automatically; outliers were identified by Grubbs' test using the statistical program Minitab (Version 17.2.1; Minitab Inc., 16801 State College, PA, USA, significance levels $\alpha=$ $0.05)$. In accordance with the relevant OECD-regulations for studies on metabolism, a single HPLC determination was run.

\section{Results}

\subsection{Vitality and stability of the RUSITEC system}

The $\mathrm{pH}$ values determined every $24 \mathrm{~h}$ up to $192 \mathrm{~h}$ were stable between $\mathrm{pH} 6.52$ and 6.83 with a mean of $\mathrm{pH} 6.70( \pm 0.07 \mathrm{SD}$; $\mathrm{n}=66$ ). The redox potentials measured at the same time were also stable between -240 and $-345 \mathrm{mV}$, with a mean of $-301 \mathrm{mV}$ ( $\pm 30 \mathrm{mV} \mathrm{SD} ; \mathrm{n}=66$ ). The colony forming assay to determine bacterial population showed an increase in colonies from $1.1 \times 10 \mathrm{E} 7$ colonies $/ \mathrm{ml}$ at the start of fermentation to 4.1 $( \pm 0.8 \mathrm{SD}) \times 10 \mathrm{E} 7$ after $120 \mathrm{~h}$ to $4.8( \pm 1.4 \mathrm{SD}) \times 10 \mathrm{E} 7$ after $192 \mathrm{~h}$. The shape, color and structure of the colonies were unchanged as a function of time.

The concentration of particles in the liquid phase of the fermenter fell in the first $24 \mathrm{~h}$ from $178.6 \times 10 \mathrm{E} 5$ particles $/ \mathrm{ml}$ to $36.3 \times 10 \mathrm{E} 5$ during the equilibration phase and then further 
decreased to a stable value of $9.2 \times 10 \mathrm{E} 5$ particles within the following timeframe up to $192 \mathrm{~h}$ (Fig. 2A). The size distribution also changed over the course of incubation (Fig. 2B). Generally, small particles were more abundant than larger particles. At the start of fermentation particles of 2-3.5 $\mu \mathrm{m}$ constituted $90 \%$, after $24 \mathrm{~h}$ they constituted $70 \%$ of all particles (Fig. 2B).

The number of protozoa decreased over time from $63 \times 10 \mathrm{E} 4 / \mathrm{ml}$ at time 0 to $1 \times 10 \mathrm{E} 4$ at $120 \mathrm{~h}$. The decrease was greatest within the first $24 \mathrm{~h}$ (Fig. 2C).

$\beta$-Glucosidase activity is expressed as units, where 1 unit cleaves $1 \mu \mathrm{mol}$ 4-nitrophenol- $\beta$-D-glucoside in $1 \mathrm{~min}$ at $\mathrm{pH}$ 7.0. Glucosidase activity showed a drop corresponding to the drop in particles after $24 \mathrm{~h}$ incubation but then remained constant at 4.8 units/1 until the end of the experiments (Fig. 2D).

\subsection{Metabolism}

The three derivatives of azole-fungicides showed distinctly different patterns of metabolism. Triazole-alanine (RT $5.4 \mathrm{~min}$ ) was cleaved to 1.2.4-triazole (RT $6.8 \mathrm{~min}$ ) after $24 \mathrm{~h}$ (Fig. 3B), leading to $67 \%$ of radioactivity as triazole after $96 \mathrm{~h}$ (Fig. 3D). Due to the dilution of the RUSITEC liquid phase by buffer over time, the absolute amount of substrate diminished and only relative distribution of radioactivity between the substrate and me- tabolite could be calculated from peak areas. No further radioactive metabolite was detected. In contrast, triazole-acetic acid (TAA) and triazole-lactic (TLA) acid were stable in the modified RUSITEC system up to 48 or $96 \mathrm{~h}$. No radioactive peak except the parent compound TAA with a retention time (RT) of $4.7 \mathrm{~min}$ (Fig. 3E-F) and of TLA with a retention time of $6.3 \mathrm{~min}$ were detectable (Fig. 3G-H).

Cleavage of octyl- $\beta$-D-glucopyranoside was very effective in forming an octanol derivative already detectable after $5 \mathrm{~min}$ of incubation (Fig. 4A), leading to complete degradation after $30 \mathrm{~min}$ (Fig. 4D). At later incubation time points up to $24 \mathrm{~h}$ an unknown metabolite with a 1 min shorter retention time than the octanol-derivative was observed (data not shown).

The resveratrol glucoside polydatin was incubated at two different concentrations. When only $15 \mathrm{mg}$ were added to the fermenter, polydatin was cleaved to resveratrol by $\beta$-glucosidase in $5 \mathrm{~min}$ (Fig. 4E), whereas after adding $142 \mathrm{mg}$ polydatin a slower cleavage over $1 \mathrm{~h}$ was observed (Fig. 4F). The metabolite resveratrol seemed stable over $6 \mathrm{~h}$ since no further peak with an absorption at $306 \mathrm{~nm}$ was observed. After $24 \mathrm{~h}$ no resveratrol was measurable. Here, as in incubations with the labelled compounds, no quantitative measurements were possible due to the dilution of the rumen fluid with buffer over time.

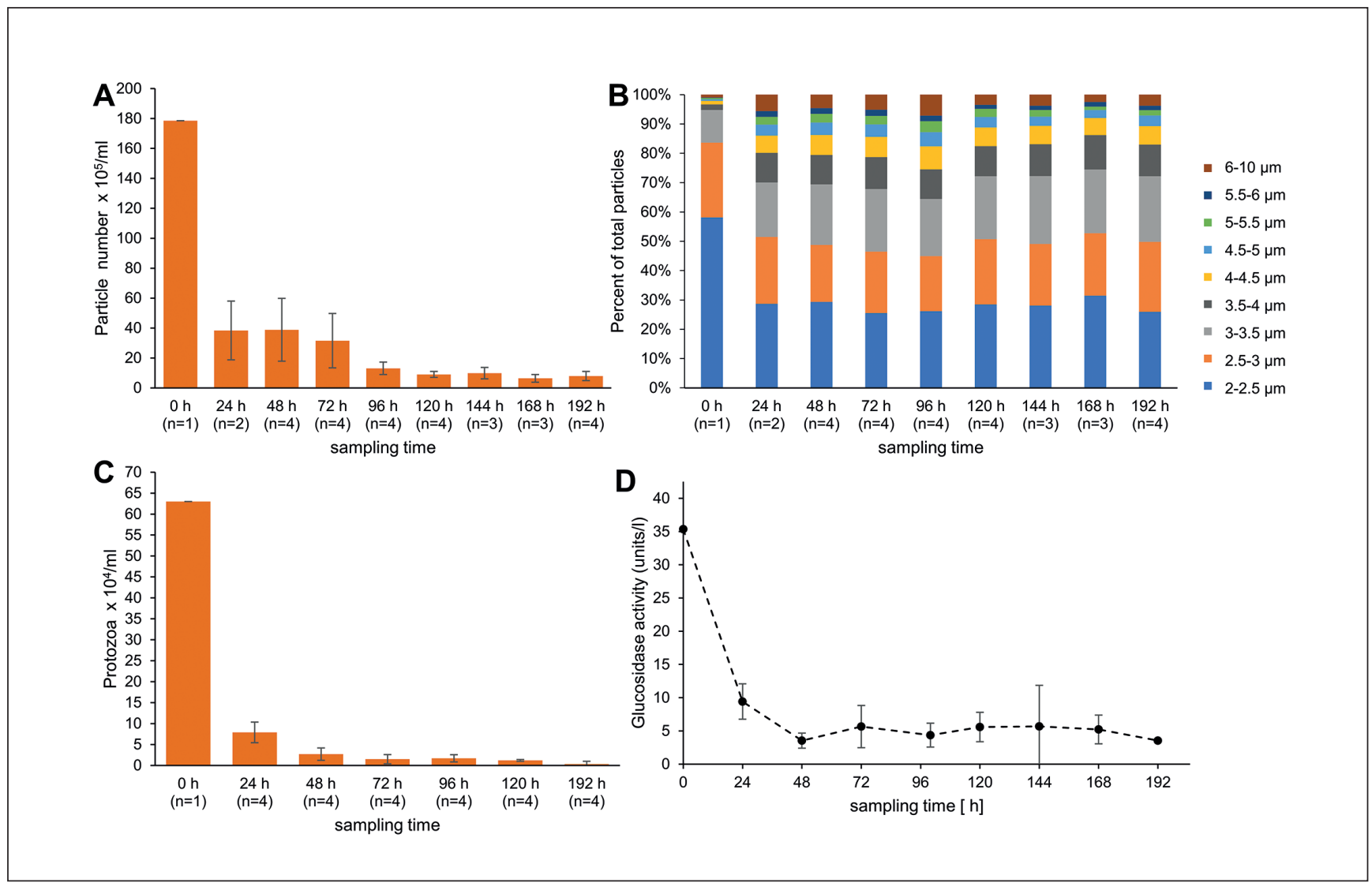

Fig. 2: Results on the microflora and its activity in the fermenter over time

$A$, Particle density $(\bar{x} \pm S D)$; $B$, Distribution of particles according to size; $C$, number of protozoa in the liquid phase $(\bar{x} \pm S D)$;

$D$, Mean $\beta$-glucosidase $(\bar{x} \pm S D), n=4$. 


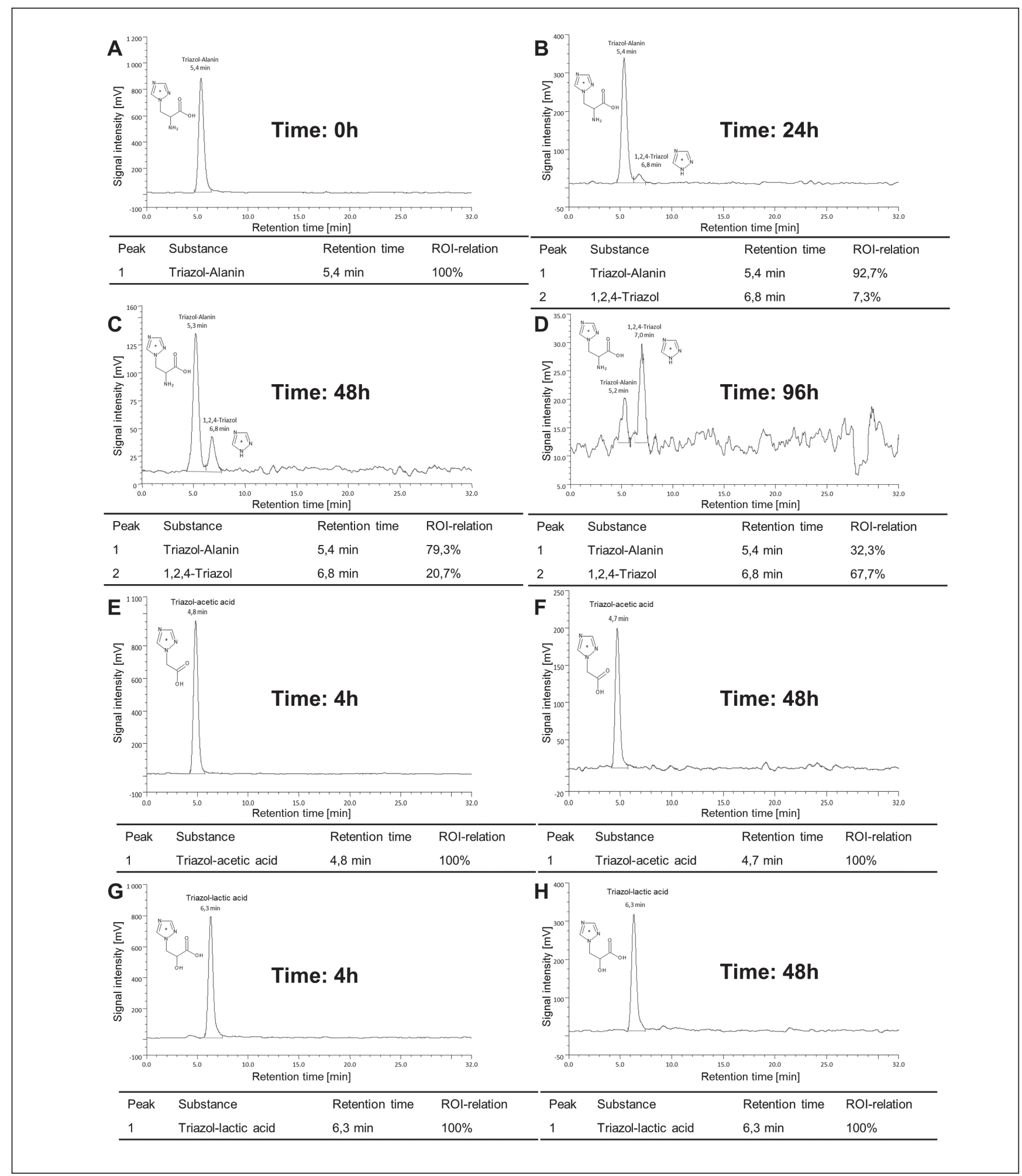

Fig. 3: Incubation of different triazole derivative metabolites and formation of 1,2,4, triazole (B-D) and stability (E-H) at different timepoints

A-D, Incubation of ${ }^{14} \mathrm{C}$-triazole-alanine at the start of the incubation (A), after $24 \mathrm{~h}(\mathrm{~B})$, after $48 \mathrm{~h}(\mathrm{C})$, and after $96 \mathrm{~h}(\mathrm{D})$; E-F, Incubation of ${ }^{14} \mathrm{C}$-triazole-acetic-acid after $4 \mathrm{~h}$ of incubation $(\mathrm{E})$ and after $48 \mathrm{~h}(\mathrm{~F}) ; \mathrm{G}-\mathrm{H}$, Incubation of ${ }^{14} \mathrm{C}$-triazole-lactic-acid at $4 \mathrm{~h}$ of incubation $(\mathrm{G})$ and after $48 \mathrm{~h}(\mathrm{H})$. 


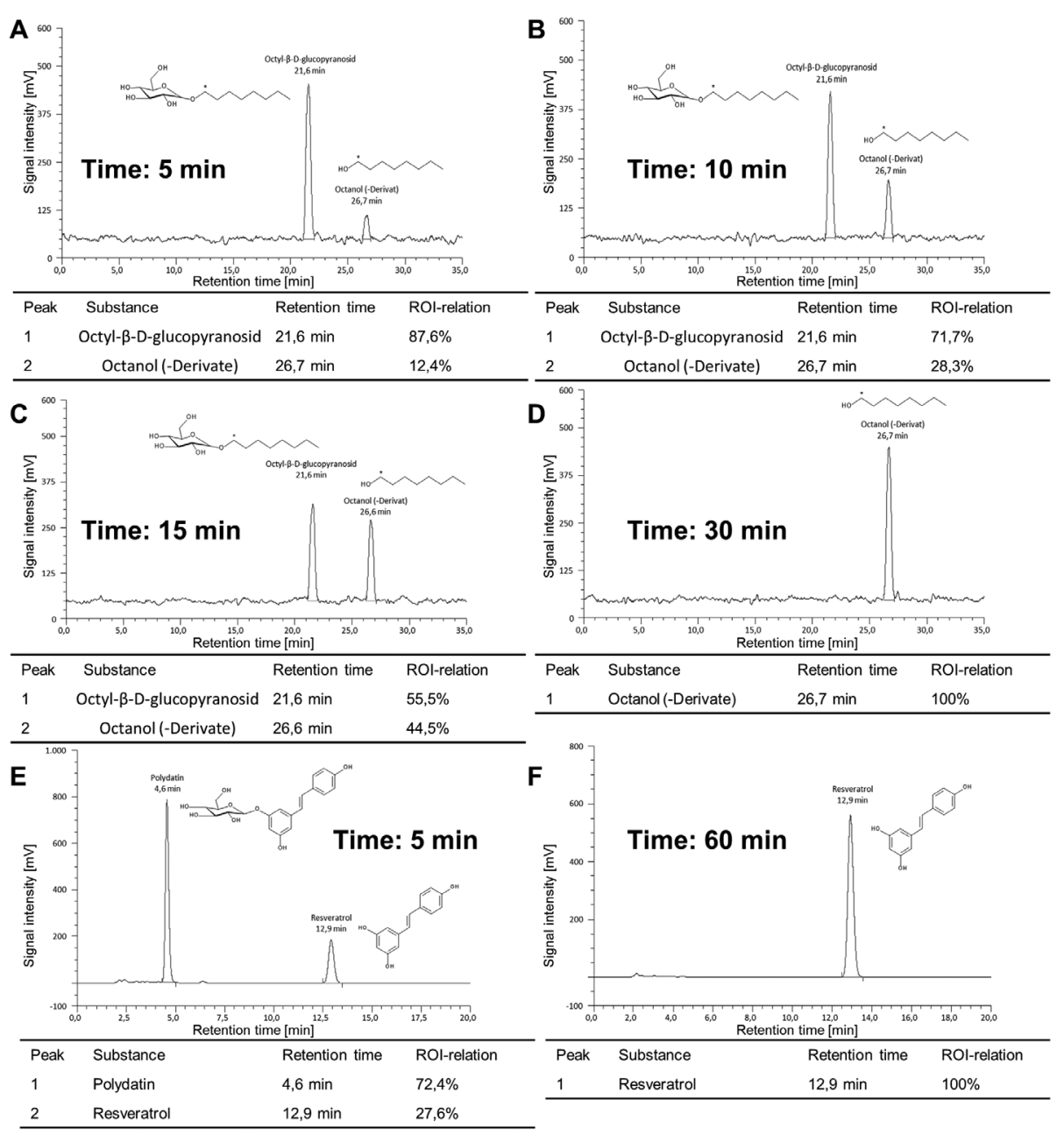

Fig. 4: Incubation of glycosides and the degradation of ${ }^{14} \mathrm{C}$-octyl- $\beta$-D-glucopyranoside (A-D) or polydatin (E-F) at different timepoints

A-D, Incubation of ${ }^{14} \mathrm{C}$-octyl- $\beta$-D-glucopyranoside for $5 \mathrm{~min}(A)$, after $10 \mathrm{~min}(B)$, after $15 \mathrm{~min}(C)$, and 30 min (D). E-F, Incubation of polydatin for $5 \mathrm{~min}(\mathrm{E})$ and $60 \mathrm{~min}(\mathrm{~F})$.

\section{Discussion}

The modified RUSITEC system was developed to facilitate incubations with radioactive compounds. The key features are a smaller volume, safe luer-lock connections and single use affordable sterile tubing. Because the conditions differ from those of the original RUSITEC system developed by Czerkawski and Breckenridge (1977), vital parameters such as $\mathrm{pH}$, redox potential and microbial populations were analyzed. The $\mathrm{pH}$ was as described in the literature and remained stable at $\mathrm{pH}$ 6.70, which is in the range of 5.0 to 7.5 recommended by Czerkawski (1986). The redox potentials equally remained stable during the experiment between -240 and $-345 \mathrm{mV}$. Different values are given in the literature for normal redox potentials in rumen. Breves and Leonhard-Marek (2010) determined values between
-250 and -300 mV, while Barry et al. (1977) determined potentials in sheep of -150 to $-260 \mathrm{mV}$ and Marounek et al. (1982) found values between -145 and $-190 \mathrm{mV}$ in goats. Marden et al. (2005) describe these discrepancies in detail and explain them by using different reference electrodes with and without corrections. A study using the same electrode as we did obtained values in the same range as measured here $(-170$ to $-300 \mathrm{mV}$; Becker, 2012). Therefore, it appears that the anaerobic conditions necessary for rumen metabolism were stable during the experimental procedures.

The determination of bacterial colonies showed an increase in colonies in the first $24 \mathrm{~h}$ followed by a stable population over time. This is in accordance with studies with a comparable approach of measurement (Hungate, 1966; Kistner, 1960). But there are also values in the literature that show higher numbers 
of $10 \mathrm{E} 10$ to $10 \mathrm{E} 11$ cells $/ \mathrm{ml}$ fresh rumen. The reason for the much lower numbers determined after plating in culture like in this approach is that many of the rumen bacteria do not grow on standardized culture plates (Hungate, 1966). As with other enterobacteria, the culture conditions for rumen bacteria are not yet optimized to enable stable growth in vitro (Breves and Leonhard-Marek, 2010). Molecular biology allows analysis of these bacteria (Wang et al., 2015) and a recent publication (Lengowski et al., 2016) has shown the dynamics of several rumen microorganisms in the RUSITEC system. These authors showed a decrease in most species in the first $24 \mathrm{~h}$ of cultivation, leading to a stable population at later incubation times. The loss of protozoa was most drastic with a factor of 10-50. This was also observed in our modified RUSITEC system, where protozoa decreased from $6.3 \times 10 \mathrm{E} 5$ protozoa to $1 \times 10 \mathrm{E} 4$ protozoa per $\mathrm{ml}$ rumen. The physiological range is wide between $10 \mathrm{E} 5$ to 10E6 protozoa per $\mathrm{ml}$ rumen (Hungate, 1966). Others also have described the loss of protozoa in the RUSITEC system (Lengowski et al., 2016; Becker, 2012; Martínez et al., 2011; Ziemer et al., 2000). The reason discussed for these observations is the loss due to buffer efflux, their long generation time of two to three days (Fuchigami et al., 1989), or adherence of protozoa to feed particles in the nylon bags (Czerkawski and Breckenridge, 1979), which are thus not accessible in the sampled liquid. There are, however, indications that loss of protozoa does not significantly influence metabolism in the rumen (Breves and Leonhard-Marek, 2010).

The number of particles determined by Coulter counting also diminished drastically in the first $24 \mathrm{~h}$. Here again the flow of buffer surely dilutes particles. In addition, the automatic system does not differentiate between inert particles and microorganisms. A stable value was reached after $24 \mathrm{~h}$. The size distribution also stabilized with particles between 2 and $3.5 \mu \mathrm{m}$ being most abundant. According to Hungate (1966), most of them are 0.4-1.0 $\mu \mathrm{m}$ wide and 1-3 $\mu \mathrm{m}$ long. Larger bacteria and smaller protozoa such as flagellates, which are 4 to $14 \mu \mathrm{m}$ in size (Breves and Leonhard-Marek, 2010), will therefore constitute most of the counted microorganisms. Our data cannot fully be compared with others, nevertheless the obtained data can be used to check changes in the fermentation conditions and be used as an internal quality check. The size distribution with the smallest particles comprising $70 \%$ of all particulate matter suggests that these were indeed live cells that attained a stable population during our experiments.

The $\beta$-glucosidase activity profile closely follows that of the particles in the rumen and reaches a stable value after $48 \mathrm{~h}$ of 4.8 ( $\pm 1.0 \mathrm{SD})$ units/l. Values in the literature are much higher but cannot be directly compared, since assay conditions as well as unit definitions are different. Agarwal et al. (2002) and Wang et al. (2015) defined 1 unit as the cleavage of $1.0 \mu \mathrm{mol}$ substrate at $\mathrm{pH} 4.5$ and $70^{\circ} \mathrm{C}$. In addition, these authors lysed cells in the rumen by vortexing and a freeze-thaw cycle, thereby liberating microbial $\beta$-glucosidase.

Metabolism studies of triazole derivative metabolites like triazole-alanine (TA), triazole- acetic-acid (TAA) and triazole-lactic-acid (TLA) (Stroeher-Kolberg et al., 2014; FAO, 2007) in the modified RUSITEC system are important contributions to the investigations requested by EFSA for plant metabolites of azole-fungicides (EFSA, 2013). Our studies show that triazole-alanine (TA) is metabolized to 1,2,4-triazole and that after $96 \mathrm{~h}$ half of the added TA is cleaved. The amounts incubated are however larger compared to the amounts expected to be ingested by ruminants in vivo. Analysis of TA in fodder resulted in values of $0.1 \mathrm{mg} \mathrm{TA} / \mathrm{kg}$ wet weight (Stroeher-Kolberg, 2014). Ruminants would therefore eat less than $1 \mathrm{mg} / \mathrm{kg}$ fodder. Sheep, which eat 1-2 $\mathrm{kg}$ feed per day, would ingest a maximum of $2 \mathrm{mg}$ TA into 51 of rumen (Orpin and Letcher, 1984). In our in vitro experiment, this would amount to $0.1 \mathrm{mg}$ TA per fermenter of $250 \mathrm{ml}$, which would then likely be rapidly metabolized to triazole. The other two test compounds triazole-acetic acid (TAA) and triazole-lactic acid (TLA) were completely stable and were not degraded (Fig. 3). The selective metabolism, namely cleavage of TA and stability of TAA has been shown in vivo in an OECD 505 study in cows (TDMDG, 2016). This shows clearly the predictivity of the RUSITEC method. No data on ruminant metabolism of TLA are currently available, neither OECD 501 nor OECD 505 studies. But, since data are requested by authorities, the data of this publication have been submitted to the British Chemicals Regulation Directorate (CRD) (TDMDG, 2016). If approved, a feeding study with 30 cows according to OECD TG 505 could be avoided.

Glycosides are very common in plants (Jenner et al., 2005; Bennett and Wallsgrove, 1994) and can be formed by intrinsic plant constituents but also from exogenous compounds such as plant protection active ingredients or their metabolites. During the approval process of plant protection products, the fate of such glycosides, ingested by ruminants, must be determined. The metabolism of octyl- $\beta$-D-glucopyranoside as model compound and polydatin, the glucoside of the plant constituent resveratrol, was analyzed. Since $\beta$-glucosidase activity in the modified RUSITEC system was stable after equilibration, an effective cleavage of both compounds was expected. This was indeed the case: octyl- $\beta$-D-glucoside was cleaved after $5 \mathrm{~min}$ to a metabolite with lower polarity than the glucoside (Fig. 4A). Unequivocal identification of this metabolite as octanol was not possible. It is therefore denoted as octanol(-derivative) in the figure. After $30 \mathrm{~min}$, the parent compound had disappeared completely and only octanol or its derivative remained. Here the amount of substrate added to the fermenter was also high to enable detection after the dilution steps caused by exchange of buffer. At physiological concentrations of a glucoside a very rapid cleavage to the aglycon can be expected.

Also, polydatin was rapidly cleaved and resveratrol was detectable after $5 \mathrm{~min}$ incubation of $142 \mathrm{mg}$ polydatin. After $1 \mathrm{~h}$ only resveratrol was detectable (Fig. 4E,F). When more physiological concentrations of $15 \mathrm{mg}$ polydatin were fermented, only resveratrol was measurable after $5 \mathrm{~min}$, showing a rapid metabolism of this glucoside under physiological conditions. Resveratrol itself seemed stable for up to $6 \mathrm{~h}$ since no further metabolite detectable at $306 \mathrm{~nm}$ was visible, but after $24 \mathrm{~h}$ no resveratrol was detectable, leading to the assumption that resveratrol is indeed further metabolized in the RUSITEC 
system. The loss of resveratrol is higher than expected by dilution of the liquid phase. Since no radioactive polydatin was available, any further metabolism could not be investigated. Nevertheless, these data show that the system has a very high metabolic capacity and seems to mimic the in vivo situation of ruminants well.

\section{Conclusions}

The regulatory agencies often require further animal studies in ruminants to investigate the fate and therefore further xenobiotic metabolism of metabolites of applied active ingredients to conduct a data-based risk assessment for pesticides (EFSA, 2015). The modified RUSITEC system presented herein can replace these additional requested xenobiotic metabolism studies in livestock for the registration process of plant protection products or veterinary drugs. The system maintains the particular properties of rumen and, after a pre-incubation time, is stable for up to 192 h. The modification described herein has not changed the metabolic capacity described over many years for the conventional 500-1000 ml RUSITEC system. The simplification and safer handling of the modified RUSITEC makes it possible to use the system in routine applications and to handle both radiolabeled and unlabeled compounds. Since the selectivity of the metabolism was proven by in vivo studies, BASF will replace in vivo animal studies on ruminant metabolism studies beyond OECD 503 by performing RUSITEC studies. The method is already included in the common method portfolio of BASF, leading to a significant contribution to the 3R strategy. Further studies comparing data with in vivo observations will show the usefulness of the system and will in future prevent many animal studies and provide alternatives to animal experiments in the sense of the 3 Rs.

\section{References}

Agarwal, N., Kamra, D. N., Chaudhary, L. C. et al. (2002). Microbial status and rumen enzyme profile of crossbred calves fed on different microbial feed additives. Lett Appl Microbiol 34, 329-336. doi:10.1046/j.1472-765X.2002.01092.x

Barry, T. N., Thompson, A. and Armstrong, D. G. (1977). Rumen fermentation studies on two contrasting diets. 1. Some characteristics of the in vivo fermentation, with special reference to the composition of the gas phase, oxidation/reduction state and volatile fatty acid proportions. J Agr Sci 89, 183-195. doi:10.1017/S0021859600027362

Becker, S. (2012). Reduziert der Zusatz von Fumarsäure die ruminale Methanproduktion durch Beeinflussung der Populationsstruktur der mikrobiellen Gemeinschaft? Gottfried Wilhelm Leibniz Universität Hannover. Naturwissenschaftliche Fakultät, Dissertation.

Bennett, R. N. and Wallsgrove, R. M. (1994). Tansley Review No. 72. Secondary metabolites in plant defence mechanisms. New Phytologist 127, 617-633. doi:10.1111/j.1469-8137.1994. tb02968.x
Breves, G. and Leonhard-Marek, S. (2010). Verdauungsvorgänge in den Vormägen. In W. von Engelhardt (ed.), Physiologie der Haustiere (380-389). $3^{\text {rd }}$ edition. Hannover, Germany: Enke Verlag.

Clippinger, A. J., Hill, E., Curren, R. and Bishop, P. (2016). Bridging the gap between regulatory acceptance and industry use of non-animal methods. ALTEX 33, 453-458. doi:10.14573/altex.1601311

Czerkawski, J. W. and Breckenridge, G. (1977). Design and development of a long-term rumen simulation technique (Rusitec). Br J Nutr 38, 371-384. doi:10.1079/BJN19770102

Czerkawski, J. W. and Breckenridge, G. (1979). Experiments with the longterm rumen simulation technique (Rusitec); Use of soluble food and an inert solid matrix. Br J Nutr 42, 229245. doi:10.1079/BJN19790110

Czerkawski, J. W. (ed.) (1986). An Introduction to Rumen Studies. Oxford, UK: Pergamon Press.

EFSA - European Food Safety Authority (2013). Reasoned opinion on the modification of the existing MRLs for tetraconazole in commodities of plant and animal origin. EFSA J 11, 3223. doi:10.2903/j.efsa.2013.3223

EFSA (2015). Outcome of the consultation with Member States, the applicant and EFSA on the pesticide risk assessment for fluroxypyr in light of confirmatory data. EFSA Supporting Publication 2015, EN-857. doi:10.2903/sp.efsa.2015.EN-857

EFSA (2016). Guidance on the establishment of the residue definition for dietary risk assessment. EFSA J 14, 4549. doi:10.2903/j.efsa.2016.4549

FAO - Food and Agriculture Organization of the United Nations (2007). Pesticide residues in food 2007 - Report of the Joint Meeting of the FAO Panel of Experts on Pesticide Residues in Food and the Environment and the WHO Core Assessment Group on Pesticide Residues. Geneva, Switzerland, 18-27 September 2007. https://bit.ly/2FST3JY

Fuchigami, M., Senshu, T. and Horiguchi, M. (1989). A simple continuous culture system for rumen microbial digestion study and effects of defaunation and dilution rates. J Dairy Sci 72, 3070-3078. doi:10.3168/jds.S0022-0302(89)79460-1

Hungate, R. E. (1966). Chapter II: The rumen bacteria. In The Rumen and its Microbes. New York, London: Academic Press. doi:10.1016/B978-1-4832-3308-6.50005-X

Jenner, H., Townsend, B. and Osbourn, A. (2005). Unravelling triterpene glycoside synthesis in plants: Phytochemistry and functional genomics join forces. Planta 220, 503-506. doi:10.1007/s00425-004-1434-z

Kistner, A. (1960). An improved method for viable counts of bacteria of the ovine rumen which ferment carbohydrates. J Gen Microbiol, 565-576. doi:10.1099/00221287-23-3-565

Lengowski, M. B., Zuber, K. H. R., Witzig, M. et al. (2016). Changes in rumen microbial community composition during adaption to an in vitro system and the impact of different forages. PLoS One 11, e0150115. doi:10.1371/journal.pone. 0150115 .

Lv, C., Zhang, L., Wang, Q. et al. (2006). Determination of piceid in rat plasma and tissues by high-performance liquid chromatographic method with UV detection. Biomed Chro- 
matogr 20, 1260-1266. doi:10.1002/bmc.693

Marounek, M., Bartos, S. and Kalachnyuk, G. I. (1982). Dynamics of the redox potential and $\mathrm{pH}$ of the rumen fluid of goats. Physiol Bohemoslov 31, 369-374.

Marden, J. P., Bayour, C., Enjalbert, F. and Moncoulon, R. (2005). A new device for measuring kinetics of ruminal $\mathrm{pH}$ and redox potential in dairy cattle. $J$ Dairy Sci 88, 277-281. doi:10.3168/jds.S0022-0302(05)72685-0

Martínez, M. E., Ranilla, M. J., Rams, S. et al. (2011). Evolution of fermentation parameters in Rusitec fermenters operated at different dilution rates and concentrate retention times. In M. J. Ranilla, M. D. Carro, H. Ben Salem and P. Morand-Fehr (eds.), Challenging Strategies to Promote the Sheep and Goat Sector in the Current Global Context (121-126). Zaragoza, CIHEAM/CSIC/Universidad de León/FAO. http://om.ciheam. org/option.php?IDOM=400

OECD (2007a). Test No. 503. Metabolism in Livestock. OECD Guidelines for the Testing of Chemicals, Section 5. OECD Publishing, Paris. doi:10.1787/9789264061873-en

OECD (2007b). Test No. 505. Residues in Livestock. OECD Guidelines for the Testing of Chemicals, Section 5. OECD Publishing, Paris. doi:10.1787/9789264061903-en

OECD (2007c). Test No. 501. Metabolism in Crops. OECD Guidelines for the Testing of Chemicals, Section 5. OECD Publishing, Paris. doi:10.1787/9789264061835-en

OECD (2007d). Test No. 502. Metabolism in Rotational Crops. OECD Guidelines for the Testing of Chemicals, Section 5. OECD Publishing, Paris. doi:10.1787/9789264061859-en

OECD (2010). Test No. 417. Toxicokinetics. OECD Guidelines for the Testing of Chemicals, Section 4. OECD Publishing, Paris. doi:10.1787/9789264070882-en

Oeztuerk, H., Schroeder, B., Beyerbach, M. and Breves, G. (2005). Influence of living and autoclaved yeasts of Saccharomyces boulardii on in vitro ruminal microbial metab- olism. J Dairy Sci 88, 2594-2600. doi:10.3168/jds.S00220302(05)72935-0

Orpin, C. G. and Letcher, A. J. (1984). Effect of absence of ciliate protozoa on rumen fluid volume, flow rate and bacterial populations in sheep. Anim Feed Sci Tech 10, 145-153. doi:10.1016/0377-8401(84)90004-X

Stroeher-Kolberg, D. I., Wildgrube, C., Mack, D. et al. (2014). Determination of Triazole Derivative Metabolites in Fruits and Vegetables Using the QuPPe Method and Differential Mobility Spectrometry (DMS). Poster EURL-SRM, 10 $0^{\text {th }}$ European Pesticide Residue Workshop (EPRW) in Dublin, 06/07 2014.

TDMDG (2016). Request for EFSA to finalise the reporting table on confirmatory data concerning the risk assessment of triazole derivative metabolites. Triazole Derivative Metabolites Addendum - Confirmatory Data. EFSA J 14, 1080.

Wang, C., Liu, Q., Zhang, Y. L. et al. (2015). Effects of isobutyrate supplementation on ruminal microflora, rumen enzyme activities and methane emissions in Simmental steers. J Anim Physiol An N 99, 123-131. doi:10.1111/jpn.12191

Ziemer, C. J., Sharp, R., Stern, M. D. et al. (2000). Comparison of microbial populations in model and natural rumens using 16S ribosomal RNA-targeted probes. Environ Microbiol 2, 632-643. doi:10.1046/j.1462-2920.2000.00146.x

\section{Conflict of interest}

The authors declare no conflicts of interest.

\section{Acknowledgments}

The work of the authors was supported by BASF SE, Crop Protection, Germany. We are grateful for the contributions of Dr Nadja Sauer (Lufa Speyer, Germany), Dr Monika Bross, Melanie Traub (BASF SE) and Dr Eva Frei. 